\title{
ANÁLISE DA COLABORAÇÃO CIENTÍFICA EM CIÊNCIAS CONTÁBEIS POR MEIO DA COOPERAÇÃO EM BANCAS DE DOUTORADO
}

João Estevão Barbosa Neto

joaoestevaobarbosaneto@gmail.com

Universidade Federal de Alfenas

\author{
Jacqueline Veneroso Alves da Cunha \\ jvacbr@yahoo.com.br \\ Universidade Federal de Minas Gerais
}

RESUMO: A partir das relações sociais dos pesquisadores, o conhecimento científico é criado e desenvolvido (Khun, 1978). Tendo por base tal premissa, este trabalho tem como objetivo analisar a colaboração científica nos cursos de pós-graduação stricto sensu na área de Ciências Contábeis no Brasil por meio da interação em bancas de doutorado. Para tanto, foi realizado um estudo descritivo, utilizando-se da Análise de Redes Sociais para identificar a estrutura da rede científica e acadêmica por meio da colaboração dos docentes dos programas de pós-graduação stricto sensu em Ciências Contábeis na participação em bancas de doutorado. Foram identificados 70 professores de 18 programas de pós-graduação stricto sensu em Ciências Contábeis que colaboraram entre si em 112 bancas de doutorado no período de 2002 a 2010. Verificou-se uma rede ainda pequena, mas que tende a evoluir, confirmando que o conhecimento científico é desenvolvido a partir das relações sociais dos atores envolvidos. Ainda, constatou-se que a criação de novos programas de pós-graduação stricto sensu e a inserção de novos docentes foi decisiva para o aumento da colaboração em bancas de doutorado.

Palavras-chave: Pesquisa em Contabilidade. Programas de Pós-graduação Stricto Sensu em Ciências Contábeis. Análise de Redes Sociais.

Artigo recebido em: 22/07/2015; Aceito em: 05/10/2015

\section{INTRODUÇÃO}

A ciência constitui uma categoria do saber formada por um conjunto de aquisições intelectuais que tem intenção de propor uma explicação racional e objetiva da realidade (JAPIASSÚ; MARCONDES, 2001). Ao se analisar essa união intelectual é possível observar as características sociais da ciência, construídas tanto pelos cientistas quanto pelos condicionantes impostos pela sociedade para seu desenvolvimento (BOURDIEU, 2004). Desse modo, a ciência pode ser vista como um trabalho essencialmente coletivo e cumulativo, onde pesquisadores e grupos de pesquisa analisam os resultados já obtidos por seus pares, buscando a geração de conhecimento e de tecnologia.

O conhecimento científico, constituído a partir de um esforço social, é obtido por meio do trabalho dos pesquisadores e pelas atividades colaborativas formadas pela interação desses. Ao pensar os resultados da ciência a partir desse aspecto social, Popper (1972) vê as ações do sujeito como determinadas pelos detalhes da situação científica. A pesquisa é desenvolvida em um contexto de troca, sendo que o conhecimento científico não se dá de forma isolada e sim pela interação entre pesquisadores, professores, alunos, profissionais, entre outros. A partir das relações sociais dos pesquisadores, o conhecimento científico é criado e desenvolvido (KHUN, 1978; KATZ; MARTIN, 1997).

Nesse sentido, observa-se uma quantidade cada vez maior de projetos de ensino, pesquisa, e extensão concebidos e executados na forma de colaboração científica e acadêmica. Wuchty, Jones e Uzzi (2007) pesquisaram 19,9 milhões de artigos e 2,1 milhões de patentes 
produzidos em mais de 50 anos, e mostraram que a produção de conhecimento passou a ser dominada por grupos ao invés de autores isolados.

É importante ressaltar que essa evolução se dá, na maior parte das vezes, no âmbito da pós-graduação stricto sensu, já que sua imagem está diretamente relacionada à pesquisa. Mello (2008) infere que o ambiente da universidade, especialmente os programas de pósgraduação stricto sensu, além de representar relevantes contribuições para a sociedade, instiga e colabora para o desenvolvimento de pesquisas e de novos conhecimentos. Assim, observase a importância da relação entre pesquisadores dos programas de pós-graduação para o desenvolvimento científico, ressaltando que essa interação pode se dar de diversas formas, por meio de diferentes indivíduos e em diversos níveis. Nesse sentido, é relevante ressaltar que, embora a coautoria seja o indicador mais utilizado para verificar a existência de colaboração científica, essa interatividade não é realizada somente pelas publicações, podendo ocorrer por meio de participação em bancas examinadoras, coautoria de livros, participação em projetos de pesquisa, participação em grupos de pesquisa, entre outras formas relacionais. Com relação à interação por de bancas examinadoras, a Coordenação de Aperfeiçoamento de Pessoal de Nível Superior (CAPES) incentiva a participação de docentes em bancas de mestrado e doutorado de fora dos programas por meio dos chamados membros externos, com o objetivo de garantir a presença de ideias, teorias e modelos de pesquisas novos (RELATÓRIO DE AVALIAÇÃO CAPES 2007-2009).

Contudo, é importante ressaltar que a relação por meio de bancas se dá em um contexto diferente da coautoria em artigos, livros e outras publicações. Um membro externo é convidado para uma banca pela sua especialização com a área e, talvez, nunca tenha conhecido ou colaborado com os outros avaliadores participantes. Segundo Godechot e Mariot (2004) o que caracteriza a formação de uma banca é o convite dos membros dessa comissão avaliadora, o que é realizado, muitas vezes, por meio de uma parceria entre o orientador e o orientado. E a intenção de ambos pode residir desde o prestígio do convidado até sua experiência na área. De acordo com os autores, no curto prazo, a diversificação da composição da banca proporciona um trabalho mais bem avaliado e aufere um destaque na posição dos participantes na comunidade acadêmica. No longo prazo, as comissões compostas em bancas colaboram para a formação de uma densa e coesa rede de acadêmicos, promovendo a reprodução da pesquisa e a extensão do grupo em sua competição com outros grupos. Desse modo, a contribuição científica e acadêmica do membro pode suscitar novas atividades de intercâmbio acadêmico. Balancieri (2004) infere que a colaboração científica é incentivada, sobretudo, pela necessidade de um apoio especializado, visando atingir os objetivos científicos e necessidade de se trabalhar próximo a outrem para adquirir novas habilidades e conhecimento tácito.

As Ciências Contábeis, como um campo do conhecimento científico, também faz uso da interação de seus pares para o desenvolvimento das atividades acadêmicas e de pesquisa da área. Observando o relacionamento entre os pesquisadores das Ciências Contábeis dentro de uma perspectiva de rede social, pode-se verificar diversas formas de organizações para a pesquisa e o estabelecimento de ideias socialmente aceitas com pretensão de contribuir com o conhecimento nesse campo científico. E como identificado em outras áreas, nas Ciências Contábeis os pesquisadores também têm buscado a colaboração entre seus pares, principalmente no que tange a coautoria de trabalhos científicos. Cruz et al. (2010b), ao analisarem a forma de organização e cooperação da produção científica entre os atores envolvidos no Congresso USP de Controladoria e Contabilidade no período 2001-2009 observaram que no primeiro triênio do evento uma relevante parcela $(32 \%)$ dos trabalhos foi realizada individualmente. Mas já no terceiro triênio do período analisado, a realização de 
estudos a partir da perspectiva colaborativa, ou seja, com mais de um autor, mostrou-se a prática mais comum, tendo sido verificada em mais de $91 \%$ do volume de publicações.

No Brasil, a colaboração científica na área contábil tem sido estudada de forma frequente (ESPEJO et al., 2009; WALTER et al., 2009; CRUZ et al. 2010a; CRUZ et al. 2010b; NASCIMENTO, BEUREN, 2010). Contudo os estudos têm como foco a cooperação por meio da participação em coautoria de artigos, não tendo sido verificada a interação por meio de outras formas acadêmicas como bancas de mestrado, bancas de doutorado, projetos de pesquisa etc. Diante desse contexto e buscando evidenciar uma análise inovadora da colaboração científica, o presente estudo tem como objetivo analisar a colaboração científica nos cursos de pós-graduação stricto sensu na área de Ciências Contábeis no Brasil por meio da interação em bancas de doutorado. Dessa forma, é possível reconhecer centros, indivíduos e grupos mais influentes no campo científico em Contabilidade, identificando a estrutura científica e acadêmica dessa área do conhecimento por uma nova visão de cooperação.

Dessa forma, tal estudo das redes pode mostrar características da realidade social contemporânea que ainda não foram inteiramente exploradas, além de evidenciar como os indivíduos, dotados de recursos e capacidades propositivas, organizam suas ações nos próprios espaços políticos em função de socializações e mobilizações suscitadas pelo próprio desenvolvimento das redes. Tal análise proporcionará, ainda, o entendimento de parâmetros de atuação que possibilitem entender como os agentes reproduzem as práticas acadêmicas e de pesquisa no decorrer do tempo.

\section{REFERENCIAL TEÓRICO}

\subsection{Redes Sociais}

De acordo com Granovetter (1973) as redes sociais podem ser definidas como um conjunto de nós ou atores (pessoas ou organizações) ligados por relações sociais ou laços de tipos específicos. Assim, pode-se entender a rede social como um conjunto de participantes autônomos, juntando ideias e recursos em torno de valores e interesses compartilhados.

A ideia de redes sociais e seus métodos de análise têm atraído de forma considerável o interesse da comunidade científica nas últimas décadas (WASSERMAN; FAUST, 1994). Marteleto (2001) infere que embora o trabalho pessoal em redes de conexões seja muito antigo, apenas nas últimas décadas as pessoas passaram a percebê-lo como uma ferramenta organizacional. Pesquisadores têm percebido que a abordagem das redes sociais pode esclarecer questões de aspecto social e comportamental nas mais diversas esferas do conhecimento.

Para Wasserman e Faust (1994) rede social consiste em um ou mais conjuntos finitos de atores e a relação ou relações entre eles, sendo a informação relacional a característica essencial da rede. De acordo com Granovetter et al. (2000, p. 219) as redes sociais podem ser definidas como:

[...] um conjunto de nós ou atores (pessoas ou organizações) ligados por relações sociais ou laços de tipos específicos. Um laço ou relação entre dois autores tem tanto força quanto conteúdo. O conteúdo inclui informação, conselho ou amizade, interesses compartilhados ou pertencimentos, e tipicamente algum nível de confiança.

Contudo, é relevante ressaltar, que a análise de redes não constitui uma teoria formal ou unitária, mas um extenso campo de investigação de estruturas sociais (MARTINS, 2009).

R. Cont. Ufba, Salvador-Ba, v. 9, n. 3, p. 135 - 153, set-dez 2015 
No mesmo sentido, Marteleto (2001) ressalta que desde os estudos clássicos de redes sociais até os mais recentes é consenso que não há uma "teoria de redes sociais" e que o conceito pode ser empregado com diversas teorias sociais, precisando de informações empíricas complementares, além da identificação dos elos e relações entre indivíduos. Assim, a análise de redes pode ser utilizada em estudos de diferentes situações e aspectos sociais.

Adicionalmente Wasserman e Faust (1994), comentam sobre alguns conceitos essenciais para a discussão da análise de redes (Quadro 1).

Quadro 1 - Conceitos fundamentais da análise de redes

\begin{tabular}{|l|l|}
\hline Ator & $\begin{array}{l}\text { Entidades sociais como indivíduos, organizações, países. O interesse da análise de } \\
\text { redes sociais é entender as ligações entre as entidades sociais e as implicações dessas } \\
\text { ligações. }\end{array}$ \\
\hline Laço relacional & $\begin{array}{l}\text { Ligação estabelecida entre um par de autores. Um laço pode ser uma transferência de } \\
\text { recurso de uma empresa para outra, a escolha de um amigo, dentre outras formas. }\end{array}$ \\
\hline Centralidade & $\begin{array}{l}\text { nível em que um ator está interligado a outros atores, ou seja, quanto maior essa } \\
\text { conexão para um determinado ator, mais central ele será. }\end{array}$ \\
\hline Densidade & $\begin{array}{l}\text { Relação entre as ligações existentes e o total de ligações possíveis entre os atores da } \\
\text { rede. }\end{array}$ \\
\hline Componentes & $\begin{array}{l}\text { Sub-redes totalmente conectadas entre si, sendo o mais simples de todos os conceitos } \\
\text { de sub-redes. São os atores de um subconjunto e todas as ligações entre eles. }\end{array}$ \\
\hline $\begin{array}{l}\text { Distância } \\
\text { geodésica }\end{array}$ & $\begin{array}{l}\text { Distância entre um par de nós é o número de laços que há no caminho mais curto entre } \\
\text { eles, ou caminho direcionado no caso de grafos direcionados, sendo que caso não exista } \\
\text { tal caminho a distância pode ser considerada indefinida ou infinita. }\end{array}$ \\
\hline
\end{tabular}

Fonte: Adaptado de Wasserman e Faust (1994)

Outro conceito é o de Small Words (Mundos Pequenos), que surgiu da limitação de análise mais precisa de redes grandes (MARTINS, 2009). Watts e Strogatz (1998) foram os autores que realizaram as medidas de Small Words, discorrendo que elas ocorrem quando os autores estão agrupados localmente (Coeficiente de Agrupamento) e, ao mesmo tempo, precisam de poucos indivíduos para contatar qualquer um dos membros da rede (Distância Média). O pressuposto fundamental é que os atores presentes em uma grande rede podem conectar-se a partir de um pequeno número de intermediários (NEWMAN, 2004).

Dessa forma, observa-se que as redes sociais podem ser estabelecidas em todos os ambientes, inclusive no acadêmico por meio da cooperação entre os pesquisadores com intuito de disseminar o conhecimento científico. Tal aspecto será abordado no próximo tópico do trabalho

\subsection{Análise de Redes no Campo da Colaboração Científica e Acadêmica}

Vanz e Stumpf (2010) inferem que o conceito de colaboração científica é amplo e que não há um consenso entre a comunidade científica sobre como considerar o auxílio prestado por outra pessoa. De acordo Katz e Martin (1997) dois cientistas colaboram quando compartilham dados, equipamentos e/ou ideias em um projeto, que resulta, geralmente, em uma pesquisa publicada em um artigo.

Vanz e Stumpf (2010) destacam que a colaboração científica tem sido definida como dois ou mais cientistas trabalhando juntos em um projeto de pesquisa, compartilhando recursos intelectuais, econômicos e/ou físicos. Entretanto, conforme ressaltam Bordons e Gómez (2000), a contribuição de cada um dos colaboradores pode se dar em âmbitos diferentes, desde a simples expressão de uma opinião sobre a pesquisa até o trabalho conjunto durante todo o decurso de um projeto. Nesse sentido é que entende-se que a colaboração científica vai além da realização de uma pesquisa, ou seja, a interação de pesquisadores em

R. Cont. Ufba, Salvador-Ba, v. 9, n. 3, p. 135 - 153, set-dez 2015 
bancas do doutorado também pode ser entendida como colaboração científica, uma vez que há uma interação de conhecimentos de diversos pesquisadores.

Weisz e Roco (1996) argumentam que uma rede de pesquisa pode ser definida como uma organização constituída por diferentes indivíduos ou grupos ligados entre si por vínculos de naturezas diversas. De acordo com Balancieri (2004) esta colaboração pode se dar por diferentes formas, e cita como exemplo alguma reflexão conjunta de ideias ou uma participação ativa em um projeto de pesquisa específico. $O$ autor ainda destaca que as cooperações podem ser classificadas de acordo com o nível em substancial ou vazia. Um exemplo é o fato de um pesquisador ser considerado colaborador apenas por fornecer material ou auxiliar em alguma atividade rotineira. Mas também pode acontecer da cooperação ser resultado de comprometimento envolvendo metas comuns, esforço coordenado e resultados ou produtos com responsabilidade e mérito compartilhados.

Glänzel e Schubert (2004) comentam sobre os motivos que levam os cientistas a colaborar entre si. E as razões são diversas, como a capacidade de acesso a agências de fomento à pesquisa; a diminuição de custos de transporte e comunicação e o aumento da disponibilidade; a aspiração pelo intercâmbio intelectual com outros pesquisadores; a obrigatoriedade exigida por pesquisas interdisciplinares e em áreas que são mais especializadas exige uma divisão de trabalho. Para Balancieri (2004) a mais óbvia razão de colaboração consiste na necessidade de um apoio especializado, visando atingir os objetivos científicos e necessidade de se trabalhar próximo a outrem para adquirir novas habilidades e conhecimento tácito.

Para Glänzel e Schubert (2004) o crescimento de coautorias internacionais é um reflexo dos aspectos relacionados à globalização da pesquisa científica e o avanço nas técnicas de comunicação entre cientistas geograficamente separados. Em seus estudos, os autores verificaram que, no princípio da década de 1980, os artigos científicos coautorados internacionalmente nos EUA, União Soviética e Japão não alcançavam a 10\%; mas que no final do século passado, o percentual aumentou e excedeu parcialmente o valor de $20 \%$. Demonstraram, ainda, que para grandes e médios países desenvolvidos, houve um crescimento entre 10 e $20 \%$ no início dos anos 1980 e de 30 a 50\% no término da década de 1990 (GLÄNZEL e SCHUBERT, 2004).

Balancieri (2004) apresentou em ordem cronológica dos estudos sobre a análise de redes de colaboração científica, ressaltando sua descrição de tais trabalhos. Não contempla todos os estudos sobre o assunto, mas os principais sob o ponto de vista das áreas de redes de colaboração científica (Quadro 3).

Quadro 2 - Cronologia das redes de colaboração na área acadêmica

\begin{tabular}{|c|c|c|c|}
\hline Década de 60 & D & $\begin{array}{l}\text { Início dos estudos; } \\
\text { Investigação de formas colaborativas; } \\
\text { Identificação dos colégios invisíveis; } \\
\text { Maioria das publicações - coautorias; } \\
\text { Coautoria entre orientador e orientando; } \\
\text { Teoria do Mundo Pequeno; } \\
\text { Seis graus de separação; }\end{array}$ & $\begin{array}{l}\text { Smith (1958), Price } \\
\text { (1963), Milgram (1967) }\end{array}$ \\
\hline Década de 70 & 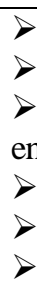 & $\begin{array}{l}\text { Áreas do conhecimento colaborativa, quais e porque; } \\
\text { Comparação entre as áreas do conhecimento; } \\
\text { Identificação dos pesquisadores, instituições e países } \\
\text { los; } \\
\text { O número de coautores correlato com seu impacto; } \\
\text { Os colégios invisíveis possuem alta produtividade; } \\
\text { Fortalecimento coautoria. }\end{array}$ & Storer (1970) \\
\hline Década de 80 & & $\begin{array}{l}\text { Questionamentos relativos à definição de colaboração; } \\
\text { Diferenças em qualificar alguém como colaborador; }\end{array}$ & Stefaniak (1982) \\
\hline
\end{tabular}

R. Cont. Ufba, Salvador-Ba, v. 9, n. 3, p. 135 - 153, set-dez 2015 


\begin{tabular}{|c|c|c|}
\hline & $\begin{array}{l}\text { Influência de artigos com maior número de coautores; } \\
\text { Contagem de coautorias como medida mais usada; } \\
\text { Fatores determinantes para a colaboração científica. }\end{array}$ & \\
\hline Década de 90 & $\begin{array}{l}\text { Colaborações nacionais em relação versus colaborações } \\
\text { internacionais; } \\
\text { geográfica; } \\
\quad \text { Fase pré-web, colaborações decrescem com a distância } \\
\text { experimentais; } \\
\text { Visão dos diferentes níveis de colaboração; } \\
\text { Junção de várias áreas para entendimento e/ou visualização } \\
\text { das redes. }\end{array}$ & $\begin{array}{l}\text { Scott (1991), Kodama } \\
\text { (1992), Katz (1993) }\end{array}$ \\
\hline Década 2000 & $\begin{array}{l}\text { Fase web, análise da colaboração na internet; } \\
\text { Relação colaboração e produtividade; } \\
\text { po Brasil, estudos da colaboração em congressos e } \\
\text { periódicos de áreas específicos. }\end{array}$ & $\begin{array}{l}\text { Newman (2001), Barabási } \\
\text { (2003), Newman (2004), }\end{array}$ \\
\hline
\end{tabular}

Fonte: Adaptado de Balancieri (2004)

No Brasil, mais especificamente na área das ciências sociais aplicadas, os estudos começaram na década de 1990. No entanto, na década de 2000 identificou-se um relevante incremento em tais pesquisas (ESPEJO et al., 200; WALTER et al. 2009; CRUZ et al., 2010a; CRUZ et al., 2010b).

Ressalta-se que os estudos referentes à colaboração entre pesquisadores e programas de pós-graduação no âmbito da produção científica têm favorecido a compreensão do conhecimento científico não como empreendimento individual, mas imerso em redes de relacionamentos. Desse modo, destaca-se a importância do crescimento de estudos que buscam analisar a estrutura de colaboração entre os pesquisadores e acadêmicos do campo das Ciências Contábeis, já que a trajetória de evolução de um determinado campo científico passa pela compreensão das relações que ocorrem entre os atores desse campo.

\section{PROCEDIMENTOS METODOLÓGICOS}

O presente estudo possui natureza descritiva (GALL et al., 2007), pois apresenta as características da relação acadêmica entre os programas de pós-graduação em Ciências Contábeis, além de estabelecer relações entre variáveis e fatos desse fenômeno.

Com relação à população e amostra do trabalho, inicialmente foi realizada a coleta do número e do nome dos professores que compõem o corpo docente de cada um dos programas de pós-graduação stricto sensu em Ciências Contábeis no Brasil por meio de visitas aos sítios eletrônicos de tais programas. Somente o programa de pós-graduação stricto sensu em Ciências Contábeis da UNB/UFRN/UFPB não disponibilizava a relação dos docentes em seu sítio eletrônico na data consultada. Para obter essa informação foi solicitado, via e-mail, ao coordenador do programa, a relação de docentes do curso de mestrado e doutorado. Nessa etapa foram identificados 253 docentes, com 3 pertencendo a dois programas. Nesse caso, os professores foram considerados vinculados aos programas nos quais faziam parte do corpo docente permanente. Dessa forma foram considerados 250 docentes dos 18 programas de pósgraduação stricto sensu em Ciências Contábeis no Brasil. Contudo, quando foi realizada a busca pelos seus currículos no sítio eletrônico do Conselho Nacional de Desenvolvimento Científico e Tecnológico ( $\mathrm{CNPq})$, verificou-se que 9 docentes não haviam atualizado seus currículos até a data de 31/12/2009, data de corte estabelecida. Esses docentes foram excluídos, restando 241 professores na amostra final. 
O espaço temporal do estudo foi de nove anos (2002-2010), tratando-se, portanto, de um estudo longitudinal. Visando obter uma análise evolutiva do campo científico e acadêmico da Contabilidade, dividiu-se o espaço temporal em três períodos: 2002 a 2004, 2005 a 2007, 2008 a 2010. A divisão do período de análise teve como objetivo diminuir os efeitos da sazonalidade dos eventos científicos e acadêmicos, além de facilitar a interpretação dos resultados.

A informação sobre a composição das bancas de doutorado foi extraída do próprio currículo da Plataforma Lattes dos docentes. Um aspecto metodológico relevante a ser considerado refere-se aos requisitos considerados na coleta de dados referentes à composição das bancas de doutorado. O primeiro desse quesito é o ano de surgimento do programa ao qual o docente faz parte. Nesse sentido foram coletadas as bancas em que ele participou após a criação dos cursos de mestrado ou doutorado de cada instituição. A segunda implicação referese ao ingresso do indivíduo no corpo docente no programa (ou programas) no qual ele esteve vinculado durante o espaço de tempo considerado na pesquisa. Assim, a coleta de dados iniciada nessa etapa da pesquisa considerou somente a participação em bancas realizada a partir de seu ingresso em um programa de pós-graduação stricto sensu em Ciências Contábeis. Por exemplo, FÁVERO, L. P. L. começou a fazer parte do corpo docente do programa de mestrado e doutorado da USP no ano de 2006, sendo então considerada a participação em banca de doutorado desse docente somente aquela realizada a partir desse ano.

Em alguns casos, determinados docentes migraram de um programa para outro nos três subperíodos analisados (2002-2004, 2005-2007 e 2008-2010). Quando isso ocorreu, o docente foi considerado do programa do qual fazia parte naquele subperíodo analisado. Quando o docente mudou de programa no meio de um triênio (por exemplo, migrou entre 2002 e 2004) ele foi considerado vinculado ao programa do qual fez parte a maior parte do subperíodo. A partir dessas premissas foram coletados, via plataforma Lattes do Conselho Nacional de Desenvolvimento Científico e Tecnológico (CNPq), todas as bancas de doutorado em que os docentes participaram. Quando as bancas encontravam-se tabuladas partiu-se para a exclusão de bancas repetidas. Ressalta-se que, em alguns casos, havia discrepância com relação às informações dos docentes, isto é, no currículo de um docente estavam determinados membros da banca e no currículo de outro constavam docentes diferentes, para a mesma banca. Nesse caso, procurou-se a defesa via internet e procedeu-se à verificação dos autores na própria tese ou site da Capes.

Como o estudo tem o objetivo de analisar a relação entre os programas, somente bancas com dois ou mais docentes de programas como membros fizeram parte da amostra. Por exemplo, em uma banca que possui três membros, e apenas um deles é docente de algum programa de pós-graduação stricto sensu em Ciências Contábeis, não há cooperação para a Análise de Redes Sociais. Após todas as etapas e critérios de composição da amostra de bancas de doutorado, chegou-se ao total de 112 bancas que fariam parte da análise. O Quadro 1 resume as etapas da coleta de bancas de doutorado.

Quadro 3 - Descrição das etapas de formação da amostra das bancas de doutorado

\begin{tabular}{|c|l|c|}
\hline Etapa & \multicolumn{1}{|c|}{ Descrição } & Quantidade de bancas \\
\hline $1^{\mathrm{a}}$ & Coleta de todas as bancas. & 825 \\
\hline $2^{\mathrm{a}}$ & Eliminação das bancas repetidas. & 112 \\
\hline $3^{\mathrm{a}}$ & $\begin{array}{l}\text { Eliminação das bancas de acordo com os critérios de datas de início do } \\
\text { programa e ingresso do docente. }\end{array}$ & 112 \\
\hline $4^{\mathrm{a}}$ & $\begin{array}{l}\text { Eliminação das bancas que não possuíam dois ou mais participantes } \\
\text { docentes. }\end{array}$ & 112 \\
\hline
\end{tabular}

R. Cont. Ufba, Salvador-Ba, v. 9, n. 3, p. 135 - 153, set-dez 2015 
A dinâmica da estrutura de relacionamentos entre os programas de pós-graduação stricto sensu na área de Contabilidade no Brasil foi analisada por meio da Análise de Redes Sociais. Considerou-se que laço relacional entre dois professores ocorre no instante em que eles participam de uma mesma banca de doutorado. Com relação aos atributos dos pesquisadores, buscou-se analisar a instituição a qual estão vinculados e o estado em que ela se localiza. Foram utilizados os softwares Microsoft Excel ${ }^{\circledR} 2007$ e Ucinet 6.0 (BORGATTI; EVERETT; FREEMAN, 2005) para análise dos dados. O Microsoft Excel ${ }^{\circledR} 2007$ foi utilizado para a tabulação dos dados e para gerar as matrizes de adjacência que alimentaram o Ucinet 6.0. Esse último software foi usado na montagem e cálculo da estrutura das redes sociais formadas pelos professores.

Importante ressaltar a limitação do método retrocitado, cujo mecanismo permite verificar apenas as disposições estruturais e seus desdobramentos referentes à interação dos pesquisadores. Dessa forma, alguns aspectos que poderiam ser explicados pela ótica dos pesquisadores não poderão ser abordados pelo fato de exigir outros tipos de métodos para a verificação.

\section{ANÁLISE DOS RESULTADOS}

Visando mapear a estrutura relacional científica e acadêmica formada pelos programas de pós-graduação stricto sensu em Ciências Contábeis foi realizada a avaliação das interações por meio de bancas de doutorado. De acordo com Godechot e Mariot (2004), a relevância da relação social em uma banca de doutorado está nos aspectos referentes aos professores para comporem a banca avaliadora. De acordo com os autores, o convite para os membros da banca é intencional, reunindo um conjunto de regras, que estabelece a legitimidade de quem é chamado e que tentará dar validade a seu veredicto. Outro aspecto é a possibilidade do próprio candidato ao título de doutor influenciar a escolha dos membros, em parceria com seu orientador. A partir de tal contexto de relação formal, de serviço de troca, de trabalho e prestígio, as bancas de doutorado passam a ter interesse técnico e social para se configurarem em uma estrutura de rede. Assim, estão evidenciadas na Figura 1 as redes formadas no período de 2002 a 2010 provenientes de participações dos professores dos programas de pósgraduação stricto sensu em Ciências Contábeis em bancas examinadoras de doutorado na área de Contabilidade. 


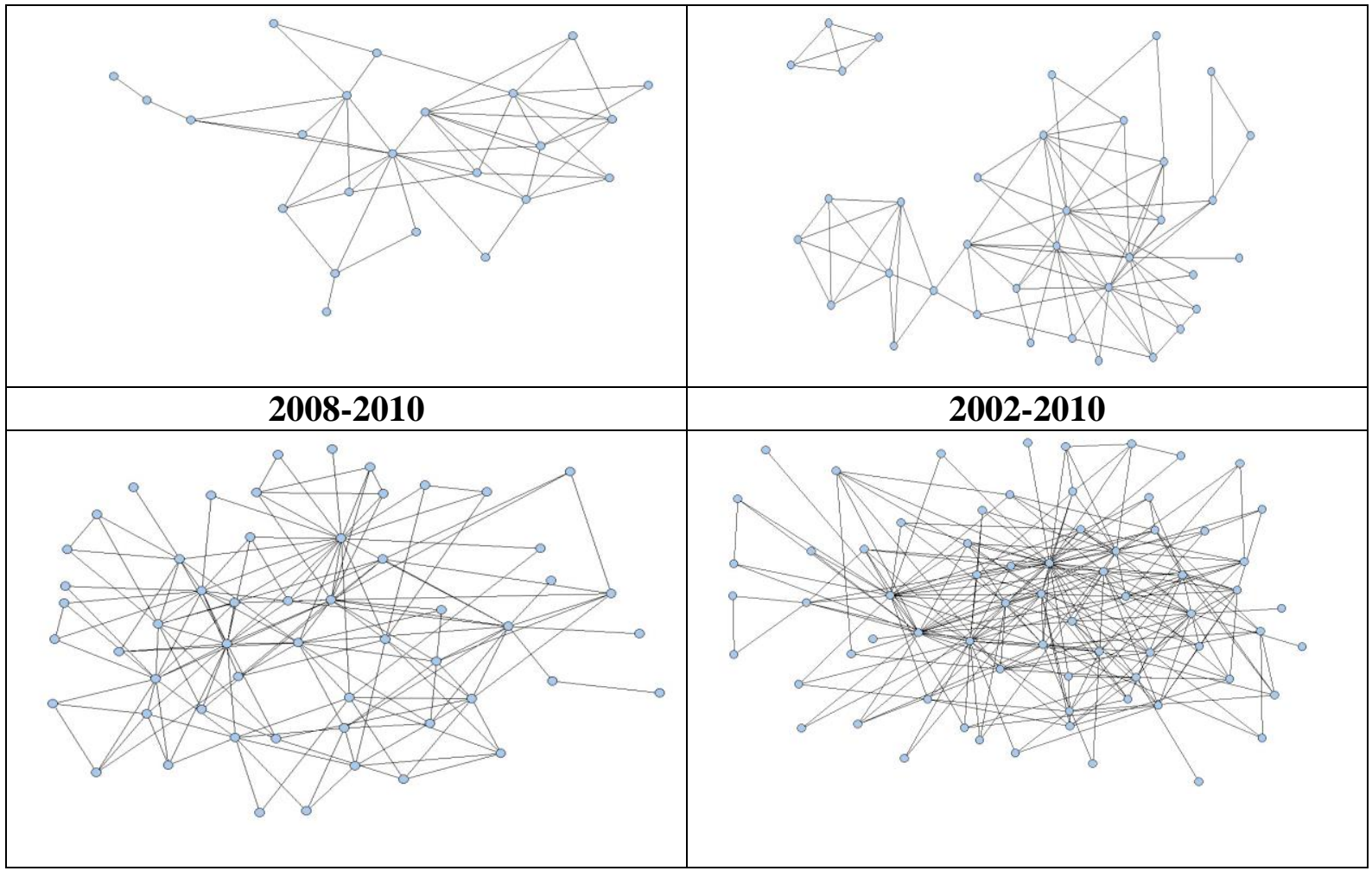

Figura 1 - Evolução da estrutura da rede de colaboração em bancas de doutorado - 2002-2010 Fonte: Resultados da pesquisa.

Embora se observe uma quantidade pequena de nós, nota-se uma grande diferença entre a rede do primeiro período analisado e a do terceiro. O fato de haver somente um doutorado até o ano de 2008 faz com que os docentes que participam de defesas de tese também sejam poucos, e também a quantidade de bancas (Figura 1). De acordo com a Associação Nacional dos Programas de Pós-Graduação em Ciências Contábeis - ANPCONT, (2010), até o ano de 2006 haviam sido titulados 153 doutores em Ciências Contábeis pela USP, e essa quantidade aumentou para $191 \mathrm{em}$ 2009. Para permitir maiores inferências foi realizada a análise dos indicadores descritivos da rede (Tabela 1).

Tabela 1 - Estatística descritiva da estrutura relacional em bancas de doutorado 2002-2010

\begin{tabular}{lcccc}
\hline & $\mathbf{2 0 0 2 - 2 0 0 4}$ & $\mathbf{2 0 0 5 - 2 0 0 7}$ & $\mathbf{2 0 0 8 - 2 0 1 0}$ & $\mathbf{2 0 0 2 - 2 0 1 0}$ \\
\hline Bancas & 31 & 33 & 48 & 112 \\
Participantes & 23 & 36 & 55 & 70 \\
Laços & 98 & 174 & 312 & 504 \\
Laços por participante & 4,26 & 4,83 & 5,67 & 7,20 \\
Densidade & $19,37 \%$ & $13,81 \%$ & $10,51 \%$ & $10,43 \%$ \\
Número de componentes & 1 & 2 & 1 & 1 \\
Número de participantes no componente principal & 23 & 32 & 55 & 70 \\
Distância Média & 2,35 & 2,67 & 2,49 & 2,33 \\
Distância Máxima (Diâmetro) & 5 & 6 & 5 & 5 \\
Coeficiente de agrupamento & 0,606 & 0,77 & 0,65 & 0,62 \\
\hline
\end{tabular}

Fonte: Resultados da pesquisa. 
De acordo com o exposto na Tabela 1, observa-se que foram analisadas 112 bancas de doutorado ao todo, sendo que a quantidade sempre aumentou de um período para o outro. A evolução mais significativa foi do segundo período para o terceiro, 45,4\% (de 33 para 45 bancas). Ao mesmo tempo, nota-se que o tamanho da rede (número de participantes), mais que duplica entre os períodos, refletindo o crescimento que o campo vem apresentando. Acompanhando as informações anteriores que refletem um aumento da rede, percebe-se também um crescimento significativo na quantidade de relacionamentos, uma vez que havia 98 laços entre 2002 e 2004 e no último período analisado foram constatados 312 laços, um crescimento de $218 \%$. Contudo, a quantidade de laços médios por docente não aumentou na mesma proporção, variando de $33 \%$ no espaço de tempo, ou seja, mesmo com o aumento da rede a colaboração não caiu. Rossoni (2006) analisa esse fato que ele denomina ótica dos agentes, onde pode-se dizer que existe uma mudança de prática de formação de bancas de doutorado, especialmente na forma pela qual os docentes buscam colaboração.

Já a densidade caiu durante os anos analisados, o que pode ter sido ocasionado pelo aumento de professores na rede. Outro desdobramento que pode ser avaliado a partir da dinâmica entre os docentes é a quantidade de componentes formados pela estrutura de relacionamento nos períodos. Nota-se que apenas entre 2005 e 2007 a rede foi formada por mais de um componente. Aqui, ressalta-se que de todas as teses analisadas apenas uma não foi defendida na USP, e sim na UNB. Isso faz com que a maior parte das bancas seja composta por docentes da própria USP, que exige apenas um docente externo na avaliação. Nota-se, dessa forma, um grupo fechado de docentes (apenas uma sub-rede), o que possibilita a maior interação entre eles.

O pequeno tamanho das redes formadas durante o espaço de tempo analisado permitiu que um docente tivesse uma pequena distância média para chegar a outro docente na rede. Entre 2002 e 2004 um docente passava, em média, por outros 2,35 para encontrar outro na rede. Já no segundo período essa distância foi de 2,67 e no último de 2,49 . A outra medida de distância entre os atores de uma rede é a distância máxima, ou seja, o diâmetro da rede. Nesse sentido, os valores encontrados também variaram pouco durante os períodos analisados, mostrando que, mesmo com o aumento do tamanho da rede, as distâncias permaneceram constantes. Adicionalmente, observa-se um elevado coeficiente de agrupamento, mostrando que a rede de docentes doutores que participam de bancas de doutorado ainda é restrita a um reduzido número de indivíduos. A Figura 2 evidencia a estrutura relacional no período de 2002 a 2010. 


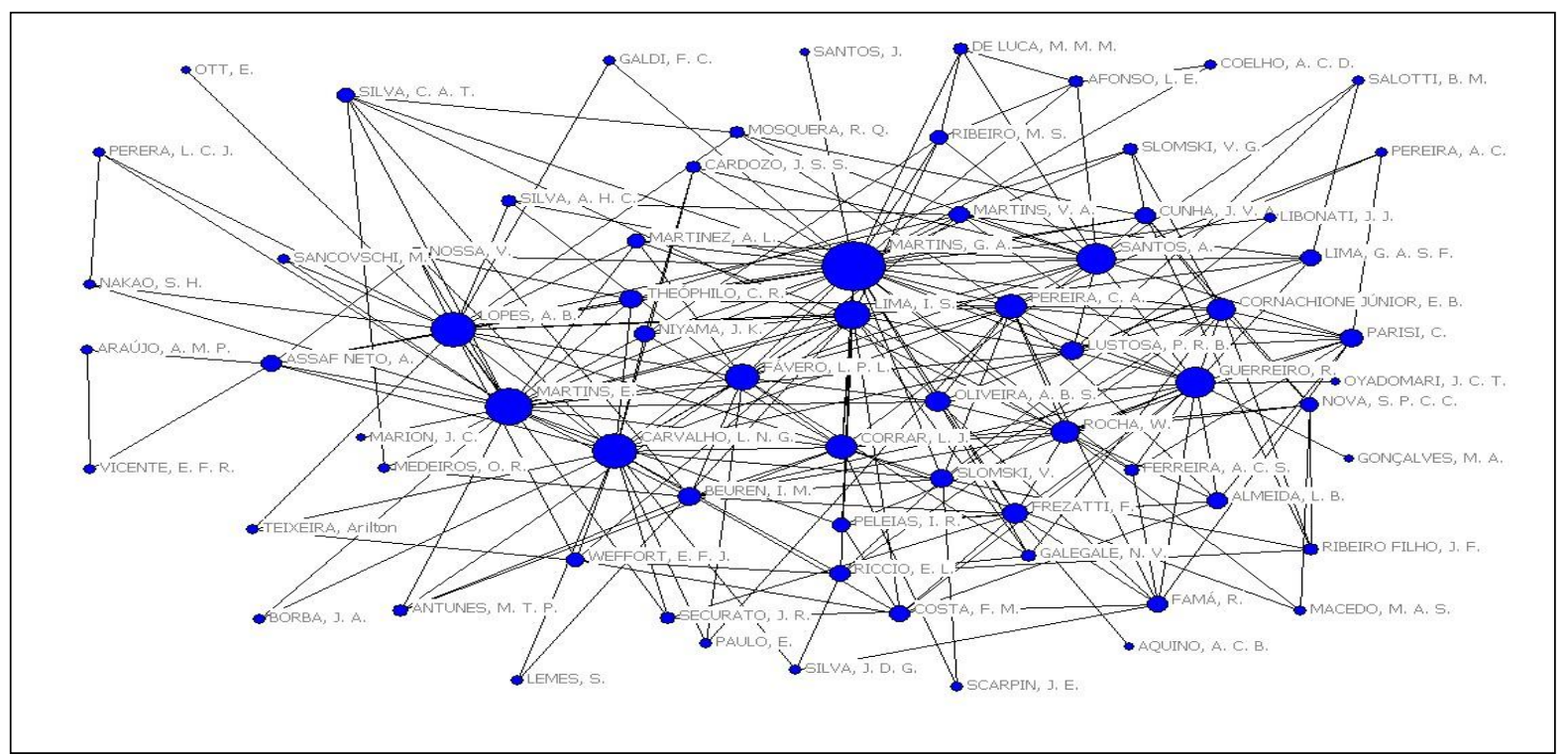

Figura 2 - Rede de colaboração em bancas de doutorado - 2002-2010

Fonte: Resultados da pesquisa.

Como observado na Figura 2, formou-se apenas um componente. Um destaque importante é que os indicadores relacionais do período todo não se mostraram, em termos de valores, tão discrepantes daqueles encontrados nos períodos separadamente, mostrando que a rede ainda é pequena, altera pouco em termos de quantidade de autores e as relações não se modificam de forma significativa (Tabela 1). Por mais que o campo científico contábil tenha evoluído, as relações por meio de bancas de doutorado não acompanharam essa evolução com mudanças relevantes. Por meio da Tabela 2 é possível observar os docentes mais centrais na rede e o número de participações em bancas de doutorado.

Tabela 2- Centralidade de grau (número de laços) e quantidade de participação em bancas de doutorado - 20022010

\begin{tabular}{lcc}
\hline \multicolumn{1}{c}{ Docentes } & Centralidade de Grau (C.G.) & Participações em Bancas (P.B.) \\
\hline MARTINS, G. A. & 34 & 29 \\
MARTINS, E. & 24 & 24 \\
CARVALHO, L. N. G. & 23 & 23 \\
LOPES, A. B. & 22 & 18 \\
GUERREIRO, R. & 19 & 17 \\
SANTOS, A. & 19 & 10 \\
LIMA, I. S. & 18 & 15 \\
\hline
\end{tabular}

Fonte: Resultados da pesquisa.

A rede está fundamentada em torno de poucos docentes, basicamente vinculados a USP, o que é justificado pela instituição ser a única que possuía o curso de doutorado até 2008. MARTINS, G. A. (C.G = 34); MARTINS, E. (C.G = 24) e CARVALHO, L. N. G. (C.G. = 23) são os docentes mais centrais, mas o primeiro se destaca com 34 interações diferentes entre 2002 e 2010 . A quantidade de participação em bancas também acompanha, na maior parte das vezes, a centralidade de grau, o que mostra que os docentes com mais interações são aqueles que mais participam. Todos os docentes citados na Tabela 2 possuem mais de 10 anos de doutoramento, mostrando que indivíduos mais experientes tendem a ser mais centrais na composição social. Verifica-se que a experiência proporciona determinados 
conjuntos de características, vinculados com o prestígio do indivíduo, como serem orientadores de programas de pós-graduação, membros e coordenadores de associações de pesquisadores, membros de conselhos editoriais de periódicos, avaliadores de artigos, representantes de órgãos oficiais, entre outros (ROSSONI, 2006).

De acordo com Newman (2004) a centralidade de intermediação possibilita uma análise de como determinados atores da rede estão abertos a outros grupos. Nesse sentido foi calculada a centralidade de intermediação dos docentes entre 2002 e 2010 (Tabela 3).

Tabela 3 - Centralidade de intermediação em bancas de doutorado - 2002-2010

\begin{tabular}{lc}
\hline \multicolumn{1}{c}{ Docentes } & Centralidade de Intermediação (C.I.) \\
\hline MARTINS, G. A. & 1.224 .034 \\
MARTINS, E. & 709.183 \\
CARVALHO, L. N. G. & 596.957 \\
LOPES, A. B. & 576.390 \\
GUERREIRO, R. & 413.288 \\
SANTOS, A. & 318.045 \\
CORRAR, L. J. & 282.229 \\
\hline
\end{tabular}

Fonte: Resultados da pesquisa.

Observa-se que a maior parte dos autores com maior centralidade de intermediação, são os que também possuem maior centralidade de grau. Ou seja, o fluxo de informação na rede formada por meio da participação em bancas de doutorado é dependente de uma minoria de docentes, o que contribui para a proliferação de relacionamentos redundantes, que não acrescentam expressivo capital social à composição estrutural (Tabela 3).

Analisando a rede interinstitucional, verifica-se que esta foi formada por todas as instituições que possuem programas de pós-graduação stricto sensu em Ciências Contábeis no Brasil, exceto a UFAM (Figura 3). Tal instituição se mostra inexpressiva nas análises relacionais, demonstrando que os docentes a ela vinculados podem vir a colaborar de forma mais relevante para o conhecimento científico contábil. Junta-se a isso o fato de seu corpo docente ser formado por apenas um doutor em Ciências Contábeis, sendo os outros de outras áreas do conhecimento.

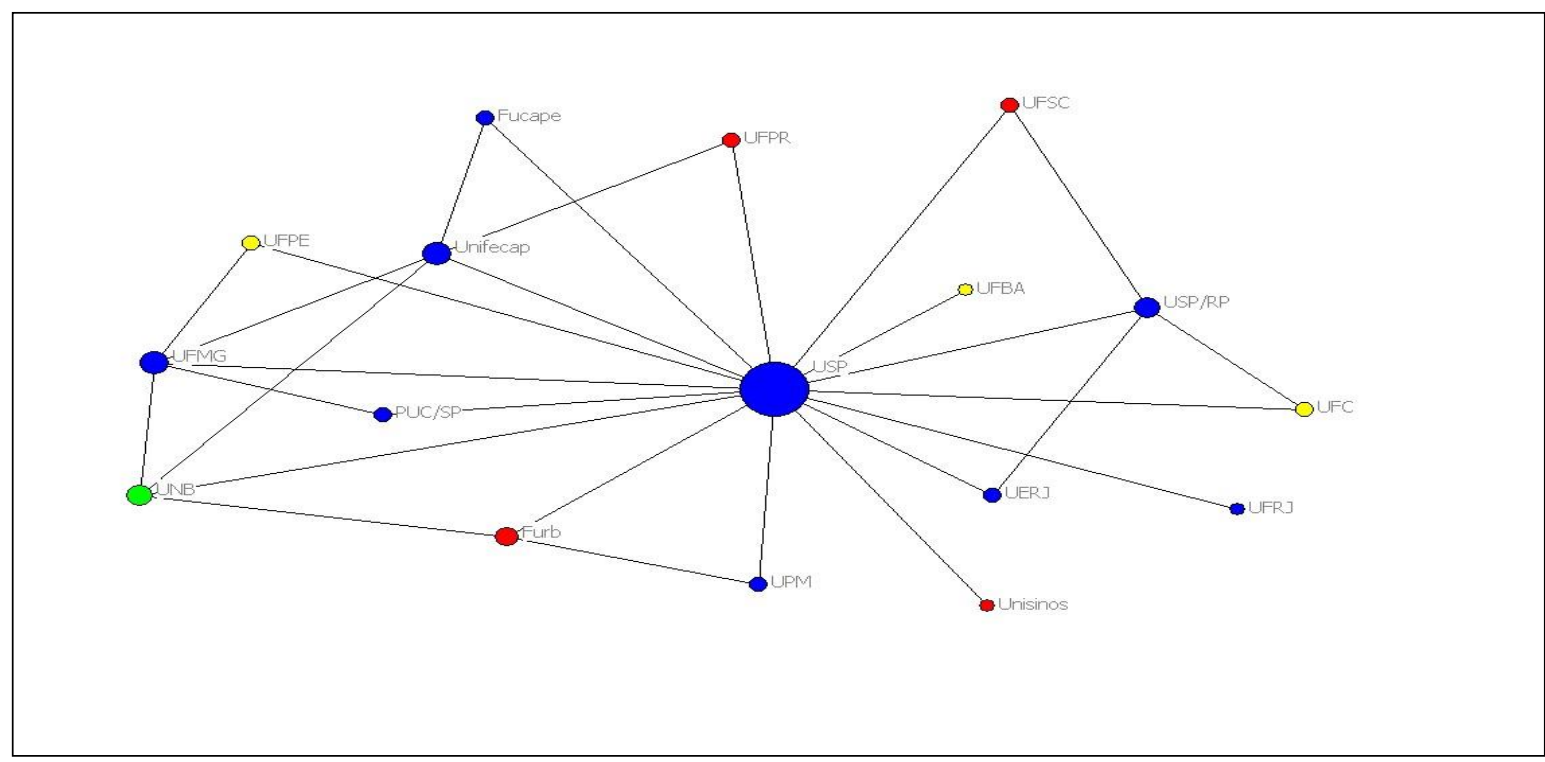

Figura 3 - Rede de colaboração em bancas de doutorado entre instituições - 2002-2010

R. Cont. Ufba, Salvador-Ba, v. 9, n. 3, p. 135 - 153, set-dez 2015 
Nota: As cores dos nós indicam as diferentes regiões geográficas nas quais os programas se situam. Fonte: Resultados da pesquisa.

A rede formada pelas instituições apresenta um caráter nacional, não se observando bancas formadas por instituições da mesma região geográfica a não ser aquelas da região Sudeste. O fato das bancas serem da USP faz com que a maior parte da composição da mesa de avaliação seja dessa instituição (Figura 3). Como apenas um membro é externo, a banca tem a possibilidade de ser composta por apenas um docente de outras regiões geográficas do Brasil. Também o fato da maior parte dos doutores em Ciências Contábeis estarem na região Sudeste faz com que a participação seja maior entre esses doutores por causa da proximidade geográfica (KATZ, 1993). Os indicadores relacionais por instituição estão expostos na Tabela 4.

Tabela 4 - Indicadores relacionais em bancas de doutorado por instituição - 2002-2010

\begin{tabular}{lccc}
\hline \multicolumn{1}{c}{ Instituição } & $\begin{array}{c}\text { Centralidade de } \\
\text { Grau (C.G) }\end{array}$ & $\begin{array}{c}\text { Centralidade de } \\
\text { Intermediação (C.I) }\end{array}$ & $\begin{array}{c}\text { Participações em } \\
\text { Bancas (P.B.) }\end{array}$ \\
\hline USP & 16 & 100.000 & 109 \\
UFMG & 5 & 2.500 & 5 \\
Unifecap & 5 & 2.500 & 14 \\
UNB & 4 & 1.000 & 20 \\
USP/RP & 4 & 1.500 & 12 \\
Furb & 3 & 0.500 & 5 \\
Furb & 3 & 0.500 & 5 \\
\hline
\end{tabular}

Fonte: Resultados da pesquisa.

A USP, como demonstrado e já esperado, foi a instituição mais central em grau (C.G. =16). Destaque para a UFMG que possui um programa relativamente novo, mas que tem sido destaque na quantidade de relacionamentos que faz (C.G. $=5)$. Com relação à centralidade de intermediação observa-se que quase $65 \%$ das instituições não influenciam no fluxo de informação na rede, pois possuem centralidade de intermediação nula (C.I. =0). A USP é a intermediadora mais eficaz, pois faz relações com todas as outras escolas (C.I. $=100.000$ ). Destaca-se que a PUC/SP, embora tenha se relacionado com apenas duas instituições entre 2002 e 2010, teve seus docentes em 13 bancas, a quarta melhor colocação. Tal fato mostra a boa capacidade de relacionamento dos docentes da PUC/SP com os docentes da USP e da UFMG, com as quais ela se relacionou. A Unisinos teve destaque na participação em bancas de mestrado, porém só teve um docente (OTT, E.) participando de uma banca de doutorado na USP (Tabela 4).

Diante de tal contexto, infere-se a dependência da ciência contábil do Brasil ao programa da USP, mostrando que tal instituição representa o núcleo científico e acadêmico da Contabilidade, com contribuição para o desenvolvimento do campo. Contudo, ressalta-se que as outras instituições também estão contribuindo para o desenvolvimento das Ciências Contábeis, principalmente nos últimos 5 anos.

Por fim, como forma de testar a hipótese de que a rede de colaboração entre programas de pós-graduação stricto sensu em Ciências Contábeis apresenta estruturas do tipo Small Worlds foram comparados os indicadores reais com os esperados de acordo com Watts e Strogatz (1998). Tais índices estão evidenciados na Tabela 5. 
Tabela 5 - Estatística de Small Worlds para redes de participação em bancas de doutorado

2002-2004 $2005-2007 \quad 2008-2010 \quad 2002-2010$

\begin{tabular}{|c|c|c|c|c|c|}
\hline \multicolumn{6}{|l|}{ Dados Observados } \\
\hline Densidade & & $19,37 \%$ & $13,81 \%$ & $10,51 \%$ & $10,43 \%$ \\
\hline Autores & $\mathrm{n}$ & 14 & 86 & 162 & 176 \\
\hline Média de laços por autor & $\mathrm{k}$ & 4,26 & 4,83 & 5,67 & 7,20 \\
\hline $\begin{array}{l}\text { Distância média (PL } \\
\text { observado) }\end{array}$ & PL & 2,35 & 2,67 & 2,49 & 2,33 \\
\hline $\begin{array}{l}\text { Coeficiente de agrupamento } \\
\text { (CC observado) }\end{array}$ & $\mathrm{CC}$ & 0,60 & 0,77 & 0,65 & 0,62 \\
\hline \multicolumn{6}{|l|}{$\begin{array}{l}\text { Dados aleatórios (WATTS; } \\
\text { STROGATZ,1998) }\end{array}$} \\
\hline $\begin{array}{l}\text { Coeficiente de Agrupamento } \\
\text { (CC esperado) }\end{array}$ & $\mathrm{k} / \mathrm{n}$ & 0,30 & 0,05 & 0,03 & 0,04 \\
\hline Distância média (PL) esperada & $(\ln (\mathrm{n}) / \ln (\mathrm{k}))$ & 1,82 & 2,82 & 2,93 & 2,61 \\
\hline \multicolumn{6}{|l|}{ Indicadores } \\
\hline PL taxa & $\begin{array}{l}\text { (PL observado/ } \\
\text { PL aleatório) }\end{array}$ & 1,294 & 0,943 & 0,848 & 0,888 \\
\hline CC taxa & $\begin{array}{l}\text { (CC observado/ } \\
\text { CC aleatório) }\end{array}$ & 1,991 & 13,736 & 18,591 & 15,156 \\
\hline Q: Coeficiente Small Word & (CC taxa/PL taxa) & 1,539 & 14,561 & 21,920 & 17,066 \\
\hline
\end{tabular}

Fonte: resultados da pesquisa.

Nesse sentido, comparando os coeficientes de agrupamento observados com os esperados, verifica-se que os primeiros são muito maiores que os aleatórios de Watts e Strogatz (1998), demonstrando que os docentes estão agrupados localmente (pequenos grupos). Com relação à distância média, o índice esperado de Watts e Strogatz (1998) foi menor que o observado somente no primeiro período (2002-2004). O coeficiente Small World (Q) também evidenciou a tendência da rede em ser Small World, pois seus valores foram superiores a 1 em todos os períodos, embora entre 2002 e 2004 seu valor tenha ficado muito próximo de $1(1,539)$. Diante dessas informações, pode-se aceitar que a hipótese da pesquisa de que a rede formada pela participação em bancas de doutorado apresentou característica de Small World nos dois últimos períodos (2005-2007 e 2008-2010) e na rede do período todo (2002-2010).

\section{Considerações finais}

O campo científico e acadêmico pode ser visto como um sistema social (KHUN, 1978). Esse campo social é formado pelas relações entre pesquisadores, professores, alunos, entre outros. As diversas possibilidades de interação entre esses elementos faz com que o campo científico e acadêmico se desenvolva. E entre essas relações sociais estão a colaboração por meio da participação em bancas de doutorado. Nesse sentido, o presente estudo teve como objetivo analisar a colaboração científica nos cursos de pós-graduação stricto sensu na área de Ciências Contábeis no Brasil por meio da interação em bancas de doutorado. Assim, foi realizado um estudo inédito a partir das relações dos programas de pós- 
graduação stricto sensu em Ciências Contábeis por meio da interação dos docentes em bancas de doutorado.

Devido ao tamanho pequeno, a rede formada pela colaboração em bancas de doutorado se mostrou relativamente densa. O menor número de docentes participantes e menor quantidade de bancas obrigam os poucos professores doutores a manterem uma relação mais intensa. Com relação aos componentes, apenas entre 2005 e 2007 a rede foi formada por mais de uma sub-rede. $\mathrm{O}$ fato da maior parte das bancas de doutorado em Ciências Contábeis ser defendidas na USP (apenas uma foi defendida na UNB) faz com que a maior parte da composição das bancas seja dos docentes da própria instituição, que exige apenas um docente externo na avaliação. O que se observou foi uma rede formada por docentes mais experientes, o que se justifica por esses indivíduos possuírem uma maior habilidade em conduzir o processo de interação necessário para a produção do conhecimento. De acordo com Rossoni (2006) a experiência proporciona determinados conjuntos de características, vinculados com o prestígio do indivíduo, como serem orientadores de programas de pós-graduação, membros e coordenadores de associações de pesquisadores, membros de conselhos editoriais de periódicos, avaliadores de artigos, representantes de órgãos oficiais, dentre outros.

A relação entre centralidade de grau e quantidade de participação em bancas de doutorado foi verificada, sendo que os docentes com maior número de relações não se modificaram de forma relevante no início do período analisado. De forma geral, os indivíduos com maior quantidade de relações foram os que apresentaram maior centralidade de intermediação, evidenciando que, embora a rede seja pequena, um grupo restrito de docentes influencia, de forma relevante, no fluxo de informação. Adicionalmente, analisando a rede formada pelas instituições que tiveram docentes participantes nas bancas de doutorado, verificou-se uma estrutura social de caráter nacional, uma vez que, embora, a maior parte das instituições que compõem as bancas de doutorado seja do Sudeste, observou-se que a USP também tem composto suas bancas com docentes de outras instituições do país. A USP tem buscado aumentar as relações e, consequentemente, contribuir para o desenvolvimento científico e acadêmico do campo contábil. Por fim, destaca-se que a rede formada pela participação em bancas de doutorado apresentou característica de Small Worlds nos dois últimos períodos (2005-2007 e 2008-2010) e na rede do período todo (2002-2010), permitindo aceitar-se a hipótese da pesquisa para esses períodos.

Apesar de um aumento na quantidade de laços formados, o número médio de laços por docente não aumentou na mesma proporção o que sugere uma mudança de prática de formação de bancas de doutorado, especialmente na forma pela qual os docentes buscam colaboração (ROSSONI, 2006). O que se observou foi uma rede formada por docentes mais experientes, o que se justifica por esses indivíduos possuírem uma maior habilidade em conduzir o processo de interação necessário para a produção do conhecimento.

De acordo com Rossoni (2006) a experiência proporciona determinados conjuntos de características, vinculados com o prestígio do indivíduo, como serem orientadores de programas de pós-graduação, membros e coordenadores de associações de pesquisadores, membros de conselhos editoriais de periódicos, avaliadores de artigos, representantes de órgãos oficiais, dentre outros.

De forma geral, verificou-se que o campo acadêmico contábil evoluiu de forma relevante com o passar do tempo. A criação de novos programas de pós-graduação stricto sensu em Ciências Contábeis foi decisiva para o aumento da interação em bancas de doutorado, fazendo com que aumentasse também a interação entre os programas. Verificou-se também que a inserção de novos docentes nos programas influenciou de forma significativa na estrutura relacional entre os programas, contribuindo para a evolução do campo. Assim, a partir desse estudo, espera-se que novas pesquisas sejam realizadas como forma de continuar 
mapeando o campo científico contábil buscando respostas para uma melhoria contínua das Ciências Contábeis.

Nesse sentido, com relação aos programas de pós-graduação stricto sensu, sugere-se a realização de pesquisas analisando a relação social formada por professores e estudantes dos cursos de mestrado e doutorado, bem como a relação entre os estudantes no interior das turmas de mestrado e doutorado. Desta forma, conclusões interessantes poderiam ser tiradas a partir da identificação da diferença entre a colaboração formada somente pelos professores (objetivo deste estudo) e as relações entre professores e alunos. Buscar as respostas para tal questionamento pode trazer importantes contribuições para o mapeamento do campo contábil. Em outro contexto, parece importante estudar de forma mais significativa, a relação entre características sociais e profissionais e os indicadores relacionais obtidos por meio da análise de redes sociais. Como verificado em outras áreas, a estrutura das relações sociais pode estar atrelada a diversas variáveis sociais e profissionais, como formação acadêmica, produtividade, gênero (masculino e feminino). Essa verificação na área contábil pode proporcionar relevantes conhecimentos sobre o perfil dos indivíduos e quais características podem interferir para definir sua posição na rede.

\section{REFERÊNCIAS}

ASSOCIAÇÃO NACIONAL DO PROGRAMAS DE PÓS GRADUAÇÃO EM CIÊNCIAS CONTÁBEIS - ANPCONT. Mestres e doutores titulados, [20-?] Disponível em: <http://anpcont.com.br/site/docs/mestdoutanpcont.pdf>. Acesso em: 15 nov. 2010.

BALANCIERI, R. Análise de redes de pesquisa em uma plataforma de gestão em ciência e tecnologia: uma aplicação à Plataforma Lattes. 2004. 117 f. Dissertação (Mestrado em Engenharia de Produção) - Universidade Federal de Santa Catarina, Florianópolis, 2004.

BARABÁSI, A. Linked: how everything is connected to everything else and what it means for business, science, and everyday life. [S. 1.]: A Plume Book, 2003.

BORDONS, M.; GÓMEZ, I. Collaboration networked in science. In: CRONIN, B.; ATKINS, H. B. (Eds.). The web of knowledge: a festschrift in honor of Eugene Garfield. New Jersey: ASIS, p. 197-214, 2000.

BORGATTI, S.P.; EVERETT, M.G.; FREEMAN, L.C. UCINET for Windows: Software for Social Network Analysis. Boston: Harvard Analytic Technologies, 2002.

BOURDIEU, P. Os usos sociais da ciência: por uma sociologia clínica do campo científico. São Paulo: UNESP, 2004.

BRASIL. Ministério da Ciência e Tecnologia. Plataforma lattes. [2--?]. Disponível em <http://lattes.cnpq.br/index.htm>. Acesso em: 10 mar. 2011.

COORDENAÇÃO DE APERFEIÇOAMENTO DE PESSOAL DE NÍVEL SUPERIOR CAPES. RELATÓRIO DE AVALIAÇÃO CAPES 2007-2009. Brasília, 2004.

CRUZ, Ana Paula Capuano; ESPEJO, Márcia Maria dos Santos Bortolocci; COSTA, Flaviano. Perspectiva colaborativa no campo de pesquisa em contabilidade gerencial: uma análise institucional no triênio 2007-2009. In: ENCONTRO ANUAL DA ASSOCIAÇÃO 
NACIONAL DOS PROGRAMAS DE PÓS-GRADUAÇÃO EM ADMINISTRAÇÃO, ENANPAD, 34., 2010, Rio de Janeiro. Anais... Rio de Janeiro: ANPAD, 2010a. CD-ROMa.

CRUZ, A. P. C. Perspectiva colaborativa no campo de contabilidade gerencial: uma análise institucional no triênio 2007-2009. 2010. 168 f. Dissertação (Mestrado em Ciências Contábeis) - Setor de Ciências Sociais Aplicadas, Universidade Federal do Paraná, Curitiba, $2010 b$.

ESPEJO, M. M. S. B. Campo da Pesquisa em contabilidade: uma análise de redes sob a perspectiva institucional. In: CONGRESSO IAAER - ANPCONT (3rd) INTERNATIONAL ACCOUNTING CONGRESS, 3., 2009, São Paulo. Anais... São Paulo: ANPCONT, 2009. CD-ROM.

GALL, M. D.; GALL, J. P.; BORG, W. R. Educational research: an introduction. 8th. ed. Boston: Person/Allyn and Bacon, 2007.

GRANOVETTER, M. S. The strength of weak ties. The American Journal of Sociology, Chicago, v. 78, n. 6, p. 1360-1280, May.1973.

GRANOVETTER, Mark . et al. Social networks in silicon valley. In: LEE, Chong-Moon; et al. (Eds.). The Silicon Valley Edge. Stanford: Stanford University Press, 2000, p. 218-247.

GLÄNZEL, W.; SCHUBERT, A. Analyzing scientific networks through co-authorship. In: GODECHOT, O.; MARIOT, N. Les deux formes du capital social: Structure relationnelle des jurys de thèses et recrutement en science politique. Revue Française de Sociologie, Paris, v. 45, n. 2, p. 243-282, Jan. 2004.

JAPIASSÚ, Hilton; MARCONDES, Danilo. Dicionário básico de filosofia. 3. ed. Rio de Janeiro: Jorge Zahar Editor, 2001.

KATZ, J. Sylvan. Bibliometric assessment of intranational university-university collaboration. 1993. 285 f. Tese (Doutorado em Ciências Políticas) - Science Policy Research Unit, University of Sussex, Brighton, UK, 1993.

KODAMA, F. Technology fusion and the new R\&D. Harvard Business Review, Boston, v. 56, n. 3, p. 70-78, Jul./Aug. 1992.

KUHN, Thomas S. A Estrutura das revoluções científicas. 2. ed. São Paulo: Perspectiva, 1978.

MARTELETO, Regina Maria. Análise de redes sociais: aplicação nos estudos de transferência da informação. Revista Ciência da Informação, Brasília, v.30, n.1, p. 71-81, jan./abr. 2001.

MARTINS, Guilherme Silveira. A Construção do conhecimento científico no campo de gestão de operações no Brasil: uma Análise sob a ótica de Redes Sociais do período 19972008. 2009. 184 f. Dissertação (Mestrado em Administração) - Escola de Administração de Empresas de São Paulo, São Paulo, 2009.

R. Cont. Ufba, Salvador-Ba, v. 9, n. 3, p. 135 - 153, set-dez 2015 
MELLO, Cristiane Marques de. Respostas estratégicas de programas brasileiros de pósgraduação (stricto sensu) em administração à Capes: proposições institucionais a partir da análise de redes de co-autorias. 2008.140f. Dissertação (Mestrado em Administração) Universidade Estadual de Maringá em consórcio com a Universidade Estadual de Londrina, Maringá, 2008.

MILGRAM, Stanley. The small world problem. Psychology Today, New York, v. 1, n. x, p. 61-67, Feb. 1967.

NASCIMENTO, Sabrina do. BEUREN, Ilse Maria. Redes sociais na produção científica dos programas de pósgradução de Ciências Contábeis do Brasil. In: CONGRESSO DA ASSOCIAÇÃO NACIONAL DE PROGRAMAS DE PÓS-GRADUAÇÃO EM CONTABILIDADE, 3., 2010, Natal. Anais... Rio Grande do Norte: ANPCONT, 2010. CDROM.

NEWMAN, M. E. J. The structure of scientific collaboration networks. Proceedings of National Academy Sciences, Stanford, v. 98, n. 2, p. 404-409, Jan. 2001.

NEWMAN, M. E. J. Coauthorship Networks and Patterns of Scientific Collaboration, Proceedings of the National of Academic Sciences, Stanford, v. 101, n. 1, p. 5200-5205, Apr. 2004.

POPPER, Karl. Conjecturas e refutações. Brasília: UNB, 1972.

PRICE, Derek J. de Solla. Little science, big science. New Cork: Columbia University Press, 1963.

RITZER, G. Sociological metatheory: a defense of a subfield by a delineation of its parameters, Sociological Theory, San Francisco, v. 6, n. 3, p. 187-200, Mar. 1988.

ROSSONI, Luciano. A Dinâmica de relações no campo da pesquisa em organizações $e$ estratégia no Brasil: uma análise institucional. 2006. 296 f. Dissertação (Mestrado em Administração) - Universidade Federal do Paraná, Curitiba, 2006.

SCOTT, John. Social network analysis: a handbook. 2 ed. London: Sage Publications, 2000. STEFANIAK, B. Individual and multiple authorship of papers in chemistry and physics. Scientometrics, Amsterdam, v. 4, n. 1/2, p. 331-337, Jul.1982.

STORER, Norman W. The internationality of science and the nationality of scientists. International Science Journal, New York, v. 22, n. 1, p. 87-104, Jan./Feb. 1970.

WALTER, Silvana Anita. et al. Uma análise da evolução do campo de ensino e pesquisa em contabilidade sob a perspectiva de redes. In: CONGRESSO USP DE CONTROLADORIA E CONTABILIDADE, 9., 2009, São Paulo. Anais... São Paulo: FEA/USP, 2009. CD-ROM.

SMITH, Michael. The trend toward multiple authorship in psychology. American Psychologist, Washington, v. 13, n. 10, p. 596-599, Oct. 1958. 
VANZ, S. A. S.; STUMPF, I. R. C. Colaboração científica: revisão teórico conceitual. Perspectivas em Ciência da Informação, v.15, n.2, p.42-55, maio./ago. 2010.

WASSERMAN, Stanley; FAUST, Katherine. Social network analysis: methods and applications. Cambridge: Cambridge University Press, 1994.

WATTS, Duncan J.; STROGATZ, Steven H. Collective dynamics of "small-world" networks, Nature, Philadelphia, v. 393, n. 4, p. 440-442, Jun. 1998.

WEISZ, J.; ROCO, M. C. Redes de pesquisa e educação em engenharia nas américas. Rio de Janeiro: FINEP, 1996.

WUCHTY, Stefan; JONES, Benjamin F.; UZZI, Brian. The increasing dominance of teams in production of knowledg, Science, New York, v. 316, n. 10, p. 1036-1039, Apr. 2007. 